\title{
Effects of Essential Oils Distilled from Some Medicinal and Aromatic Plants against Root Knot Nematode (Meloidogyne hapla)
}

\author{
${ }^{1}$ FELEK, AF; ${ }^{2}$ OZCAN, MM; ${ }^{*}$ AKYAZI, F \\ ${ }^{*}$ Department of Plant Protection, ${ }^{2}$ Department of Field Crops, Faculty of Agriculture, Ordu University, 52200, TURKEY \\ *Corresponding Author Email: farukakyazi@hotmail.com
}

\begin{abstract}
Essential oils of medicinal and aromatic plants are important and promissing to manage the nematological problems in agriculture. In this study, five of the plants including Origanum onites, Salvia officinalis, Lippia citriodora, Mentha spicata and Mentha longifolia for egg hatching inhibition and four of the plants including Mentha piperita, Foeniculum vulgare, Coriandrum sativum and Ocimum basilicum for juvenile mortality were tested on Meloidogyne hapla under laboratory conditions. The oils were achieved by using water distillation method with a Clevenger apparatus. As the results of egg hatching trial, the highest egg hatching inhibition rate was found as $54 \%$ for $O$. onites. In addition, the other inhibition rates varied as $31.4 \%, 21.6 \%, 23.8 \%, 25.7 \%$ for the other plants, $S$. officinalis, $M$. longifolia, M. spicata and L. citriodora, respectively. Essential oil of each plant components were determined by gas chromatography (GC). Carvacrol was found as the main component $(68.8 \%)$ of $O$. onites followed by Thujone $27.7 \%$ for S. officinalis, I-Menthone $76.9 \%$ for M. longifolia, Carvone $27.1 \%$ for M. spicata and Citral $19.3 \%$ for L. citriodora. For the juveile mortality, Mentha piperita showed the highest mortality rate as $93.2 \%$ and was followed by $F$. vulgare $72.9 \%$, C. sativum $69.3 \%$ and $O$. basilicum $64.9 \%$. The main component of the used plants were Carvone $39.3 \%$, Anethole $40.2 \%$, Linalool $81.3 \%$ and Linalool $54.6 \%$, respectively.
\end{abstract}

\section{DOI: https://dx.doi.org/10.4314/jasem.v23i8.3}

Copyright: Copyright (C) 2019 Felek et al. This is an open access article distributed under the Creative Commons Attribution License (CCL), which permits unrestricted use, distribution, and reproduction in any medium, provided the original work is properly cited.

Dates: Received: 30 December 2018; Revised: 14 July 2019; Accepted 22 July 2019

Keywords: Essential oil, Medicinal and aromatic plants, Meloidogyne hapla

The root-knot nematodes, Meloidogyne spp, are one of the most economically damaging genera of plant parasitic nematodes on horticultural and field crops (Andrés et al., 2012) and synthetic nematicides were used to manage nematode yield losses problem until realizing some side effects of them. Especially, the increasing recognition that nematicidal residues became a health problem promoted much more research for safe and cheap alternative methods of nematode control. Natural products provide such an alternative model for plant-parasitic nematodes and essential oils of the plants are one of the resources to be mentioned for future alternative use for nematode management. The nematicidal activity of some plant essential oils has been demonstrated against Meloidogyne spp. (Oka, 2000; Chitwood, 2002; Zasada et al., 2006). Some investigations so far were carried out to prove the effectiveness of the oils on Meloidogyne species. Abd-Elgawad and Omer (1995) pointed out that essential oils of Mentha spicata and Mentha longifolia inhibited the egg hacthing of Meloidogyne incognita $92.2 \%$ and $82.6 \%$, respectively. Chatterjee et al., (1982) and Walker et al. (1996) reported that essential oils of $O$. basilicum, $M$. piperita, and $M$. spicata have nematicidal activity. Oka (2001) tested the inhibition effects of ten components of the oils on Meloidogyne javanica egg hatching and found that four of the components are promising to inhibit egg hatching. Ibrahim et al., (2006) examined the nematicidal activity of 18 plants and the components of the oils belonging to the plants. Among the components, the hatching of $M$. incognita eggs was completely inhibited at low concentrations $(2,4 \mathrm{mg}$ liter $^{-1}$ ) of carvacrol, thymol, and linalool. Joen et al. (2016) showed that Alpinia galanga significantly reduced hatching of Meloidogyne hapla eggs at 7, 14, and 21 days after treatment and even at the end of 21 th day, the mean number of hatched eggs was below 10 individuals. Some effects of the oils or components were also observed on juveniles of Meloidogyne species. Accordingly, the oils of Foeniculum vulgare, Origanum syriacum and Mentha microphylla caused $86 \%, 65 \%$ and $56 \%$ juvenile mortality (J2) of $M$. incognita at $100 \mathrm{mg} / \mathrm{L}$ concentration, respectively (Ibrahim et al., 2006). In another experiment, the essential oils of $F$. vulgare, Mentha rotundifolia and Mentha spicata contributed the immobilization of $M$. javanica juveniles (J2) more than $98 \%$ at $800 \mu 1 /$ liter after 48 hours (Oka et al., 2000). Similarly, the plants, F. vulgare and Mentha pulegium were the plants causing $100 \%$ mortality on the $M$. hapla juveniles 
after the exposure with the $1000 \mu \mathrm{g} / \mathrm{mL}$ dose for 24 hours (Joent et al., 2016).

As seen on the previous investigations, the oils are effective on egg inhibition of major root knot nematodes by their different concentrations, constitutes and exposure times. In this context, different medicinal and aromatic plants may be the substitution according to their different constitutes which are the component of the essential oils. Meloidogyne hapla population extracted from infected kiwifruit roots was multiplied on tomoto and used in this study. This nematode species is known to have a wide host range affecting more than 550 crop and weed species (Jepson, 1987). It is found to be a common parasite of kiwifruit in different countries in the world (Sale, 1985). It has been reported in Chile, New Zeland, United States, Iran, China, Korea and Turkey
(Akyazi et al., 2017; Haygood et al., 1990; Philippi et al., 1996; Ma et al., 2007; Watson et al. 1992).

The aim of this investigation is to determine the nematicidal activity of some medicinal and aromatic plants on $M$. hapla egg-hatching inhibition and juvenile mortality. By obtaining positive results, that will be possible to give recommendations to kiwifruit growing farmers and to contribute the literature.

\section{MATERIAL AND METHODS}

Plant materials: All medicinal and aromatic plants used in this study were obtained from the experimental greenhouse of the Ordu university. The nine plant species and part of the plant used for oil extraction are presented in Table 1.

\begin{tabular}{lll}
\multicolumn{3}{c}{ Table 1. Plant species, common name and parts of the plant used in this study. } \\
\hline Plant species & Common name & Plant parts \\
\hline Origanum onites & Oregano & Flowers, stems, leaves \\
Salvia officinalis & Sage & Leaves \\
Lippia citriodora & Lemon verbena & Leaves, seeds \\
Mentha spicata & Spearmint & Leaves \\
Mentha longifolia & Mint & Leaves \\
Mentha piperita & Peppermint & Leaves \\
Foeniculum vulgare & Fennel & Seeds \\
Coriandrum sativum & Coriander & Seeds \\
Ocimum basilicum & Basil & Leaves \\
\hline
\end{tabular}

Distillation of the oils from the plants: Different part of the medicinal and aromatic plants were used for essential oil extraction. The essential oils from parst of the plants were extracted using water distillation method with a Clevenger system. Fifty grams of each plant were submitted to hydrodistillation with a clevenger-type apparatus according to the European Pharmacopoeia and extracted with $500 \mathrm{ml}$ of distilled water for $120 \mathrm{~min}$. Then the oil per plant was collected, stored at $4{ }^{\circ} \mathrm{C}$ until used.

Preperation of nematode inoculum: The inoculum of Meloidogyne hapla obtained from infected kiwifruit roots (Actinidia deliciosa A. Chev.) and replicated on Rutgers tomato (Lycopersicon lycopersicum) as pure culture in pot cultures was used for the trials. Egg masses was handpicked from tomato roots and sterilized by sodium hypochlorite solution $(\mathrm{NaOCl})$ $(2.5 \%)$ for $4 \mathrm{~min}$. with hand-shake (Hutangura et al., 1998). The egg suspension was washed through sieve of 500 meshes and eggs retained on the sieve were poured into beher glass containing distilled water in order to condense the sterilized eggs. The eggs suspansion was adjusted to a final concentration of 100 egg/per ml distilled water and used for hatching assay. To mortality assay, the eggs were transferred to a hatching chamber and incubated for 24 hours in the dark at room temperature $26 \pm 2^{\circ} \mathrm{C}$. As last, the fresh hatched juveniles were adjusted as $40 \mathrm{~J}_{2} \mathrm{~S} / \mathrm{ml}$ distilled water as inoculum.

Chemical analysis of essential oils: The essential oils of plants were analyzed with an Agilent Technology 7890A GC system coupled to a 5975C inert MSD with Triple-Axis Detector (Agilent Technologies) on a capillary column [Agilent Technologies HP-5ms (30 $\mathrm{m} \times 0.25 \mathrm{~mm}$ I.D. $\times 0.25 \mu \mathrm{m}$ film thickness)]. GC temperature program was as follow: Initial temperature was $60^{\circ} \mathrm{C}$ and increased to $240^{\circ} \mathrm{C}$ at a rate of $4^{\circ} / \mathrm{min}$. Inlet temperature was $250^{\circ} \mathrm{C}$. Spectra were obtained for the range of $50-550 \mathrm{~m} / \mathrm{z}$. The GC temperature program was run with helium as carrier gas, at a flow rate of $1 \mathrm{~mL} / \mathrm{min}$ and injections in split mode (1:200). The mass-spectrometer interface temperature was set to $250^{\circ} \mathrm{C}$. The temperature of the ion source was $230^{\circ} \mathrm{C}$, electron energy $70 \mathrm{eV}$ and quadruple temperature $150^{\circ} \mathrm{C}$. The injection volume was $1 \mu \mathrm{L}$.

Trial and Treatment: The treatments were arranged in a completely randomised designed with three replicates. For the homogenisation process of the oils, $2 \%$ gum arabic solution was used and $4 \mu \mathrm{l}$ oils was added into $1 \mathrm{ml}$ filtered gum arabic solution to prepare the last stock solution. Five $\mathrm{ml}$ of stock solution was added into petri dishes ( $35 \mathrm{~mm}$ diam.) and $1 \mathrm{ml}$ of $\mathrm{M}$. 
hapla egg suspension (about 100 eggs) and $1 \mathrm{ml}$ of juvenile suspension (about $40 \mathrm{~J}_{2}$ ) were pipeted into the petri dishes to create total $6 \mathrm{ml}$ volume. Gum arabic solution was used as control. The plates were incubated at $\left(26 \pm 2{ }^{\circ} \mathrm{C}\right)$ in the dark. Inhibitory effect of egg hatching was recorded after 7 days exposure to oils. At the end of the trial, cumulative hatched and unhatched eggs were counted under Zeiss inverted light microscope at $40 \mathrm{X}$ magnification. In addition, after 24 hours, the juveniles were washed under tap water on a 500 mesh sieve and left in the new petri dishes with water during another 24 hours and then observed under Leica (S8APO) stereo microscope as dead and alive juveniles by touching. As last, Abbott's formula was used to calculate egg hatching inhibition and juvenile mortality rates. The trial was carried out once.

Statistics: Before ANOVA, the assumptions which are data normality and homogenenity of variance were tested. If the assumptions fited, then, the variables were analysed by one-way ANOVA. The mean results of ANOVA were compared in letters by Tukey's posthoc test. All calculations were performed with Minitab 17 statistical software. The alpha level was prefered as $5 \%$.

\section{RESULTS AND DISCUSSION}

The nematicidal activity of essential oils from medicinal and aromatic plants against M. hapla second-stage juveniles (J2) and eggs was evaluated under laboratory conditions. The results of the treatments revealed that there is a significant difference between the groups for the trial of egg hatching inhibition, but not for those of juvenile mortality. The highest success for egg hathing inhibition was valid for $O$. onites and for juvenile mortality was for M. piperita with the probable success contributed by the highest constitutes as carvacrol and carvone, respectively. The other rates was also mentioned below as sperate headlines for hathing inhibition and juvenile mortality.

Egg hatching inhibition: The essential oils of the tested five plants revealed significant inhibition activity ranging between 21.6 - $54 \%$. The highest inhibition activity belongs to the solution of $O$. onites $54.0 \%$ and the other inhibition rates varied as $31.4 \%, 21.6 \%$, $23.8 \%, 25.6 \%$ for the other plants, S. officinalis, $M$. longifolia, M. spicata and L. citriodora, respectively. The level of the contitutes per plant was given in table 4. Carvacrol was detected as the highest $(68.8 \%)$ among the constitutes of $O$. onites and the most effective component on egg-haching inhibition of M. hapla. By consideration the min. and max. effects of this plant oil, the lowest inhibition rate is begining with $51.4 \%$ (Table
2.). This is the evidence to show the relatively high potantial of the plant for nematode management. Even the I-Menthone is the highest level $(76.9 \%)$ among the constitutes for $M$. longifolia, the effectiveness of the plant was lowest in comparison to the others. The other constitute rates were close to each other as Thujone 27.8 $\%$ for S. officinalis, Carvone $27.1 \%$ for M. spicata, Citral $19.3 \%$ for L. citriodora.

Table 2. Tested plant, inhibition rates and highest constitutes of the

\begin{tabular}{lll}
\hline Plants & $\begin{array}{l}\text { Mean inhibition } \\
\text { rates (\%) and SE }\end{array}$ & $\begin{array}{l}\text { Minimum- } \\
\text { Maximum (\%) }\end{array}$ \\
\hline O. onites & $54.0 \pm 2.2 \mathrm{a}^{*}$ & $51.4-58.3$ \\
S. officinalis & $31.4 \pm 5.1 \mathrm{~b}$ & $21.3-36.7$ \\
L. citriodora & $25.6 \pm 1.5 \mathrm{~b}$ & $23.1-28.2$ \\
M. spicata & $23.8 \pm 4.5 \mathrm{~b}$ & $14.9-28.9$ \\
M. longifolia & $21.6 \pm 3.4 \mathrm{~b}$ & $14.8-25.1$ \\
\hline p-value & 0,000 &
\end{tabular}

* Different letters next to the values in the column indicate significant differences at $p<0.05$

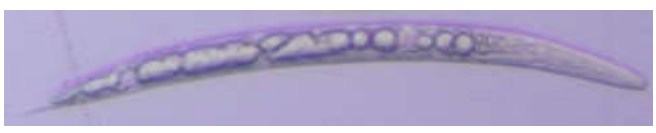

Fig 1. Appearance of dead second stage juvenile of M. Hapla

Table 3. Tested plants for juvenile mortality and obtained results

\begin{tabular}{llc}
\hline Plants & $\begin{array}{l}\text { Mean mortality } \\
\text { rates (\%) and SE }\end{array}$ & $\begin{array}{l}\text { Minimum- } \\
\text { Maximum \%) }\end{array}$ \\
\hline M. piperita & $93.2 \pm 0.7 \mathrm{a}$ & $91.7-93.9$ \\
F. vulgare & $72.9 \pm 11.1 \mathrm{a}$ & $51.5-88.5$ \\
C.sativum & $69.3 \pm 18.5 \mathrm{a}$ & $34.1-96.8$ \\
O. basilicum & $64.9 \pm 15.4 \mathrm{a}$ & $35.6-88.1$ \\
\hline p-value & \multicolumn{3}{c}{0.48} \\
\hline
\end{tabular}

Juvenile mortality: Four essential oils of medicinal and aromatic plants were tested for juvenile mortality (Table 3). There was no significant differences among the essential oils of the tested plants, but high mean mortality rates which are more than $60 \%$ for each one. The mean mortality rates ranged between 64.9 - 932 $\%$. Mentha piperita showed the highest death rate as $93.2 \%$ and was followed by Foeniculum vulgare 72.9 $\%$, Coriandrum sativum $69.3 \%$ and Ocimum basilicum $64.9 \%$. These results are also consistant with min-max rates which are waved as similar like means. When considered the constitutes, the main component of the used plants were Carvone 39.3\%, Anethole 40.2\%, Linalool $81.3 \%$ and Linalool $54.6 \%$, respectively (Table 4). Even the rates of Linalool were different for Coriandrum sativum and Ocimum basilicum, the mortality rates are almost similar for both mean and min-max parameters. As result, the impacts are promising for the management of M. hapla 
species. The further vision must be based on trying the pure main consitute of the plants if there is similar affect on nematode. This will also be benefical to confirm if the impact is coming directly from the main constitute or not. When the dead nematodes were observed under the microscope, it's appearance was straight or straight with very few bent. The intestinal system of the larvae was damaged and small bubbles were observed in the form of swellings (Fig 1).

Table 4. Chemical constitutes of essential oils distilled from nine medicinal and aromatic plant

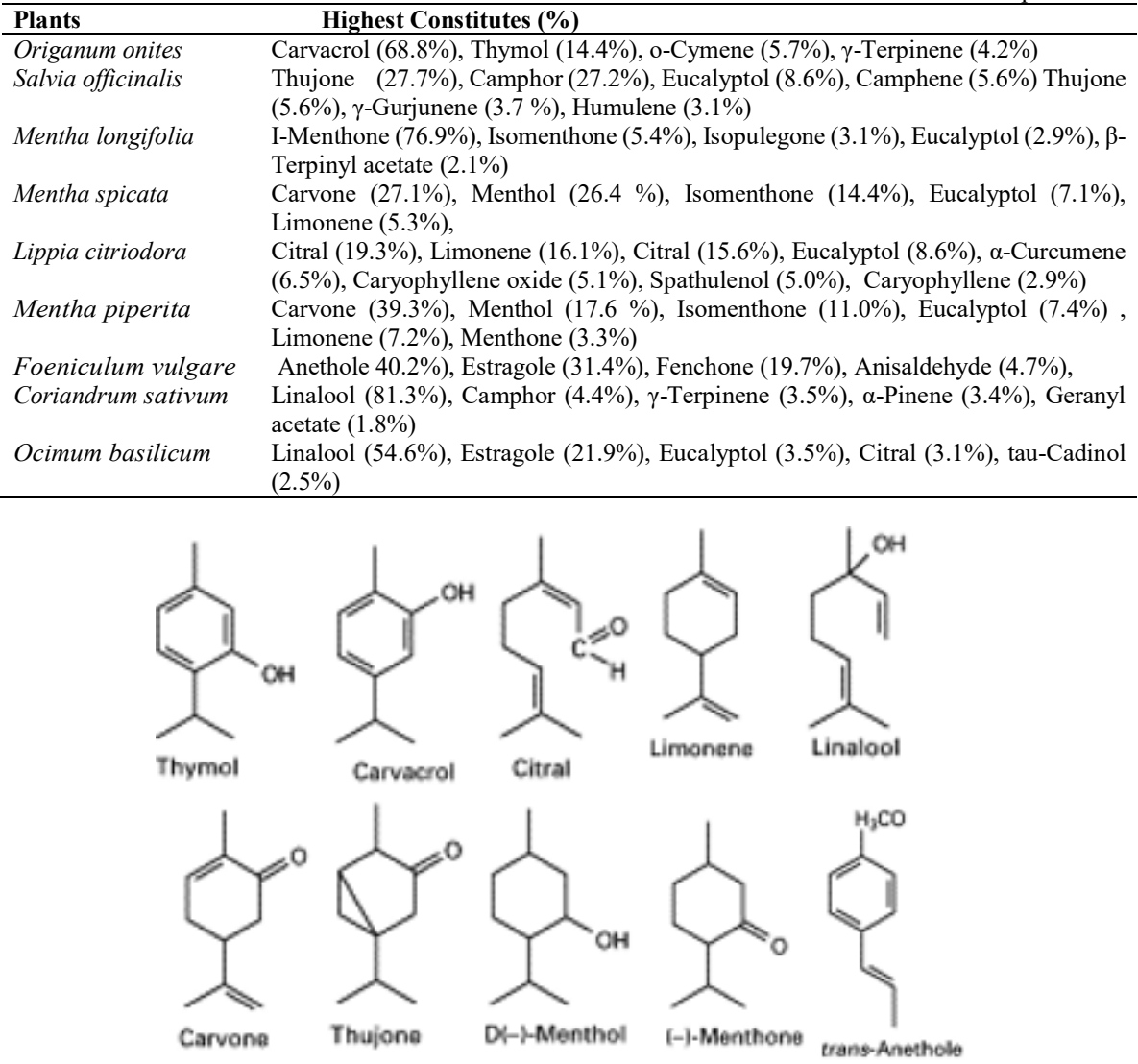

Fig 2: Chemical structures of the major constituents in essential oils.

In the present study, the examined essential oil solutions were the subjects of high nematotoxic effect on egg hatching inhibition and juvenile mortality on $M$. hapla. Even there were by now high numbers of researches on essential oils with root knot nematodes, the focus has happened mainly on other Meloidogyne species beyond $M$. hapla. Therefore, the results of present study were discussed by comparing M. hapla with other Meloidogyne species. Firstly, the most effective plant in the present study was $O$. onites on the highest egg inhibition rate and this effect probably was the result of the major constitute, carvacrol. The previous researches also proved the promising effects of carvacrol. Oka (2001) considered the nematicidal activity of carvacrol as intermediate level and it effectively reduced the root galling caused on plant by $M$. javanica in case of applied at $30 \mathrm{mg} / \mathrm{kg}$ soil. In addition, Carvacrol at $100 \mathrm{mg} / \mathrm{kg}$ increased the plant fresh shoot weight into greatest level among the all applications. Ibrahim et al. (2006) used again pure Carvacrol on the eggs of $M$. incognita and observed almost completely inhibited hatching. They reported that hatching did not exceed $6 \%$ with carvacrol at $2 \mathrm{mg}$ $\mathrm{I}^{-1}$ and carvacrol at $4 \mathrm{mg} \mathrm{L}^{-1}$ showed the inhibition effect mainly in the first week. The other plants of the present study were $S$. officinalis, $L$. citriodora, $M$. spicata, $M$. longifolia to observe their effectiveness on egg hathing inhibition. Ibrahim et al. (2006) observed that $S$. officinalis extract inhibited egg hatching of $M$. incognita more than $33 \%$ at the end of six weeks, in our study the inhibition rate of the oil was $31.4 \%$ against $M$. hapla eggs at the end of one week. The third plant showed the effectiveness against $M$. hapla eggs was L. citriodora. Essential oil of this plant was 
previously reported against Bursaphelenchus xylophilus with very low (1.9\%) efficacy (Kim et al., 2011), but in our study that was considerably high, at $25.6 \%$, against $M$. hapla eggs. Another plant at past, $M$. spicata was used against $M$. incognita and the oil of the plant suppressed the M. incognita eggs at $94 \%$ after 5 days (Andress et al., 2012) or at the end of 16 days, hacthing of the nematode eggs was also inhibited as $92.2 \%$ (Abd- Elgawad, 1995), but in our investigation, the suppression rate was $23.8 \%$ for $M$. hapla eggs after seven days. As the last plant, oil of $M$. longifolia inhibited the egg hatching of $M$. incognita as $82.6 \%$ at the end of 16 days (Abd- Elgawad, 1995), but our result showed the rate as $21.6 \%$ for M. hapla eggs after seven days. On the other hand, the juvenile (J2) mortality/immobilisation was the other part of the our research and the promissing results were achieved according to the four plants, $M$. piperita, $F$. vulgare, $C$. sativum, $O$. basilicum. The peppermint, $M$. piperita was the most successful plant by creating the highest mortality rate, $93.2 \%$ after 24 hours against $M$. hapla and also evaluated by now in different studies on the other root knot nematodes. For example, M. javanica juveniles were immobilised at $71.8 \%$ after 2 days by the effect of $M$. piperita essential oil $(1,000 \mu \mathrm{l} /$ liter $)$ (Oka et al., 2000). As a different species, M. incognita juveniles died at rate, $35 \%$ after 24 hours at 1000 ppm concentration (Pnadey et al., 2000). The oil of second plant, $F$. vulgare caused $67.4 \%$ mortality on the $M$. hapla juveniles after the exposure with the 1000 $\mu \mathrm{g} / \mathrm{mL}$ dose for 24 hours (Joen et al., 2016). The mortality of the same plant for $M$. incognita juveniles after $24 \mathrm{~h}$ exposure of the oil was $86 \%$ at $100 \mathrm{mg} \mathrm{l}^{-1}$ (Ibrahim et al., 2006). Our mortality result for $F$. vulgare was $72.9 \%$ after 24 hours on M. hapla juveniles. The last two plants of our study were $C$. sativum and $O$. basilicum which shared the same highest constitute, Linalool, and close mortality rates, $69.3 \%$ and 64.9 , respectively. C. sativum was applied on B. xylophilus and caused mortality as $100 \%$ on the nematode after $24 \mathrm{~h}$ with the dose $2 \mathrm{mg} / \mathrm{mL}$ (Kim et al., 2008). In case of the effectiveness for $O$. basilicum oil, the different concentrations $0.5,0.1,0.02 \%$ showed a mean $91.4 \%$ mortality on the juveniles of $M$. incognita (Gill, et al., 2001). As seen from the published studies, the number of publications are limited for M. hapla, but the effectiveness of plants used in our study is consistent with the previous investigations conducted other nematode species. Therefore, it is possible to emphasize that the egg hathing inhibition or jujvenile mortaliy results of the plants based on essential oils are promising to modify for nematode management.

In conclusion, our results suggest that essential oils showed nematicidal potential for the management of
M. hapla in present study. Among the tested plants $O$. onites and M. piperita were found the most effective for egg hatching inhibition and juvenile mortality, respectively. A mortality rate of more than $50 \%$ was observed. However, further experiments are needed to evaluate nematicidal activity under field conditions with nematode species.

\section{ACKNOWLEDGEMENTS}

We would like to thank Ordu University for supporting this study under Research Grant Contract No: AR1653.

\section{REFERENCES}

Akyazi, F; Joseph, S;. Felek, AF; Mekete, T (2017). Mitochondrial haplotype-based identification of root-knot nematodes, Meloidogyne arenaria and Meloidogyne hapla, infecting kiwifruit in Turkey. Nematropica 47:34-48.

Andrés, MF; González-Coloma, A; Sanz, J; Burillo, J; Sainz, P (2012). Nematicidal activity of essential oils: a review. Phytochemistry Reviews, 11(4), 371-390.

Abd-Elgawad, MM; Omer, EA (1995). Effect of essential oils of some medicinal plants on phytonematodes. Anzeiger für Schädlingskunde, Pflanzenschutz, Umweltschutz, 68(4), 82-84.

Chatterjee, A; Sukul, NC; Laskar, S; Ghoshmajumdar, S (1982). Nematicidal principles from two species of Lamiaceae. J. Nematol. 14:118-120.

Chitwood, DJ (2002). Phytochemical based strategies for nematode control. Annual Review of Phytopathology 40: 221-249

Gill, K; Mehta, SK; Malik, MS; Malik, OP; Walia RK (2001), Toxicity of methanolic leaf extracts and essential o1ls from various plants to the root-knot nematode Meloidogyne incognita. Nematol. medit. 29: 219-222.

Haygood, RA; Saunders, JA; Miller, RW (1990). Widespread occurrence of Meloidogyne incognita on kiwifruit in the coastal areas of South Carolina. Plant Disease 74:81.

Hutangura, P; Jones, MGK; Heinrich, T (1998). Optimisation of culture conditions for in vitro infection of tomato with the root-knot nematode Meloidogyne javanica. Australasian Plant Pathology, 27 (2): 84-89. 
Ibrahim, SK; Traboulsi, AF; El-Haj, S (2006). Effect of essential oils and plant extracts on hatching, migration and mortality of Meloidogyne incognita. Phytopathologia Mediterranea, 45(3), 238-246.

Jepson, SB (1987). Identification of root-knot nematodes (Meloidogyne species) Wallingford, UK: CAB International.

Jeon, JH; Ko, HR; Kim, SJ; Lee, JK (2016). Chemical compositions and nematicidal activities of essential oils on Meloidogyne hapla (Nematoda: Tylenchida) under laboratory conditions. 농약과학회지/, Korean J. Pestic. Sci. 20(1), 30-34.

Oka, Y; Nacar, S; Putievsky, E; Ravid, U; Yaniv, Z; Spiegel, Y (2000). Nematicidal activity of essential oils and their components against the root-knot nematode. Phytopathology, 90(7), 710715.

Oka, Y (2001). Nematicidal activity of essential oil components against the root-knot nematode Meloidogyne javanica. Nematology, 3(2), 159164.

Kim, J; Seo, SM; Lee, SG; Shin, SC; Park, IK (2008). Nematicidal activity of plant essential oils and components from coriander (Coriandrum sativum), oriental sweetgum (Liquidambar orientalis), and valerian (Valeriana wallichii) essential oils against pine wood nematode (Bursaphelenchus xylophilus). J. Agric. Food Chem.56(16), 7316-7320.

Kim, J; Seo, SM; Park, IK (2011). Nematicidal activity of plant essential oils and components from Gaultheria fragrantissima and Zanthoxylum alatum against the pine wood nematode, Bursaphelenchus xylophilus. Nematology, 13(1), 87-93.
Ma, KC; Jo, YS;. Kim, BH; Lim, DG (2007). Seasonal occurrence and aspects of root-knot nematodes in major kiwifruit cultivation areas of Korea. 753: VI International Symposium on Kiwifruit, Rotorua (New Zealand). Acta Horticulturae (ISHS) 753:719-724.

Pandey, R; Klra, A; Tandon, S; Mehrotra, N; Singh, N; Kumar, S (2000). Essential oils as potent source of nematicidal compounds. $J$. Phytopathology, 148(7-8), 501-502.

Philippi, I; Latorre, BA; Perez, GF; Castillo, L (1996). Identification of the root-knot nematodes (Meloidogyne spp.) on kiwifruit by isoenzyme analysis in Chile. Fitopatologia 31:96-101.

Sale, PR (1985). Kiwifruit culture. Wellington, New Zealand: Government Printer. P. 61.

Walker, JT; Melin, JB (1996). Mentha piperita, Mentha spicata and effects of their essential oils on Meloidogyne in soil. J. Nematol. 28:629-635.

Watson, RN; Wilson, EA; Marsden, RS (1992). Distribution of plant parasitic nematodes in the rhizosphere of kiwifruit. Acta Horticulturae 297:537-543.

Zasada, IA; Klassen, W; Meyer, SLF; Codallo, M; Abdul-Baki, AA (2006). Velvetbean (Mucuna pruriens) extracts: impact on Meloidogyne incognita survival and on Lycopersicon esculentum and Lactuca sativa germination and growth. Pest Manage. Sci. 62: 1122-1127. 